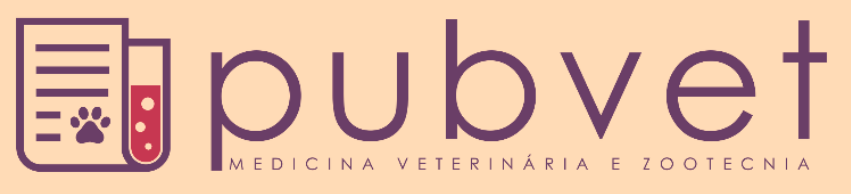

https://doi.org/10.31533/pubvet.v15n02a755.1-6

\title{
Feocromocitoma unilateral em fêmea canina: relato de caso
}

\author{
Laura Martins Mattioni ${ }^{1 *} \mathscr{G}$, Janine Mayer Perius ${ }^{1}$, Marcelo Galiotto Baú1, Maria Andréia \\ Inkelmann ${ }^{2} 9$, Cristiane Beck ${ }^{2} 9$ \\ ${ }^{I}$ Graduandos em Medicina Veterinária, Universidade Regional do Noroeste do Estado do Rio Grande do Sul - UNIJUÍ, Departamento de \\ Estudos Agrários. Ijuí - RS. Brasil. \\ ${ }^{2}$ Docentes da Universidade Regional do Noroeste do Estado do Rio Grande do Sul - UNIJUÍ, Departamento de Estudos Agrários. Ijuí - RS. Brasil. \\ *Autor para correspondência, E-mail: laura.m.mattioni@ gmail.com
}

Resumo. Feocromocitoma é uma neoplasia rara de células cromafins, localizado nas adrenais, que apresenta importância por ter a capacidade de incitar crises hipertensivas potencialmente fatais. Os sinais clínicos estão relacionados com a liberação de catecolaminas. A ressecção cirúrgica é o tratamento definitivo, mas o tratamento clínico também se mostra profícuo. Objetivou-se descrever um caso de feocromocitoma em uma cadela de nove anos, a qual apresentava hematomas cutâneos e perioculares, comportamento apático, anorexia há quatro dias e polidipsia. A paciente foi recebida no Hospital Veterinário da UNIJUÍ, e após consulta clínica e internação, a tutora optou pela eutanásia e necrópsia motivada pela baixa adesão da cadela ao tratamento. $\mathrm{O}$ animal foi encaminhado para o laboratório de Patologia Veterinária da mesma instituição que evidenciou a adrenal direita com proliferação de células vacuolizadas focalmente extensa, relativo a feocromocitoma. Diante disso, o médico veterinário deve conhecer e considerar este tipo de neoplasia.

Palavras-chave: Catecolaminas, neoplasia maligna, tumor de adrenal

\section{Unilateral pheochromocytoma in canine female: Case report}

\begin{abstract}
Pheochromocytoma is a rare neoplasm of chromaffin cells, located in the adrenals which are important for having the ability to incite potentially fatal hypertensive crises. The clinical signs are related to the release of catecholamines. Surgical resection is the definitive treatment, but the clinical treatment also proves useful. The objective was to describe a case of pheochromocytoma in a nine-year-old female dog, who had cutaneous and periocular hematomas, apathetic behavior, anorexia for four days, and polydipsia. The patient was received at the Veterinary Hospital of UNIJUÍ, and after clinical consultation and hospitalization, the tutor opted for euthanasia and necropsy motivated by the dog's low adherence to treatment. The animal was sent to the Veterinary Pathology laboratory of the same institution that evidenced the right adrenal gland with a proliferation of vacuolated cells focally extensive, concerning pheochromocytoma. Therefore, the veterinarian must know and consider this type of neoplasia.
\end{abstract}

Keywords: Catecholamines, malignant neoplasm, adrenal tumor

\section{Feocromocitoma unilateral en hembra canina: reporte de un caso}

Resumen. Feocromocitoma es una neoplasia rara de células cromafines, situado en las glándulas suprarrenales que es importante para tener la capacidad de incitar crisis hipertensivas potencialmente fatales. Los signos clínicos están relacionados con la liberación de catecolaminas. La resección quirúrgica es el tratamiento definitivo, pero el tratamiento clínico también es útil. El objetivo fue describir un caso de feocromocitoma en 
un hembra canina con edad de nueve años, que tenía hematomas cutáneos y perioculares, comportamiento apático, anorexia durante cuatro días y polidipsia. La paciente fue recibida en el Hospital Veterinario de UNIJUÍ, y después de la consulta clínica y hospitalización, la tutora optó por la eutanasia y necropsia motivada por la baja adherencia por parte de la paciente frente al tratamiento. El animal fue enviado al laboratorio de Patología Veterinaria de la misma institución que evidenció la suprarrenal derecha con proliferación de células vacuoladas focalmente extensa, relacionado con feocromocitoma. Por lo tanto, el veterinario debe conocer y considerar este tipo de neoplasia.

Palabras clave: Catecolaminas, neoplasma maligno, tumor suprarrenal

\section{Introdução}

O feocromocitoma, tumor raro originado de células cromafins chamados de feocromócitos, ocorrem na medular da adrenal e também nos paragânglios do sistema nervoso simpático. São responsáveis por 0,01 a $0,13 \%$ dos tumores caninos (Coelho et al., 2011). Esta neoplasia é a causa de $0,1 \%$ a $0,5 \%$ dos casos de hipertensão arterial, e classificam-se como inativos ou ativos, não invasivos ou invasivos, benignos ou malignos (Almeida \& Silva, 2009; Maher \& McNiel, 1997). Quando ativos, possuem a capacidade de sintetizar hormônios tais como adrenalina, noradrenalina, e eventualmente, dopamina. Nesses casos, o paciente apresenta taquicardia, fraqueza, edema, hipertrofia cardíaca, inquietação, hipertensão e outros sinais clínicos relacionados à liberação de catecolaminas.

Os tumores inativos, por sua vez, geram sintomatologia clínica por compressão e invasão de estruturas adjacentes como vasos, como por exemplo, a veia cava caudal (Almeida \& Silva, 2009; Maher \& McNiel, 1997). Comumente são unilaterais e a adrenal acometida demonstra-se aumentada com pouco tecido normal remanescente (Morris, 2007).

$\mathrm{Na}$ Medicina Veterinária, detém relevância significativa por ter a capacidade de incitar crises hipertensivas potencialmente fatais, principalmente durante induções anestésicas, procedimentos propedêuticos invasivos, cirurgias de diferentes modalidades ou demais situações de estresse (Malachias \& Vinicius, 2002). Daleck \& Nardi (2016) realizaram um estudo com 61 casos de feocromocitoma em cães e constatou que esta neoplasia se desenvolve frequentemente em cães de meia idade a idosos. Metástases podem ocorrer no fígado, linfonodos regionais, baço e rins (Morris, 2007). Não há predisposição sexual, sendo as raças Poodle, Pastor Alemão e Dobermann Pinscher as mais acometidas por essa neoplasia (Carvalho \& Jericó, 2014).

Macroscopicamente, os feocromocitomas são multilobulados com coloração entre marrom a amarelo, rosa ou vermelho devido a hemorragias e áreas necrosadas. Microscopicamente, as células alternam de poliédricas ou cúbicas a células pleomórficas com núcleos hipercromáticos (Capen, 2002).

Os exames laboratoriais de rotina podem demonstrar: anemia, ocasionada pelas hemorragias focais dos tumores, hemo-concentração, trombocitose e leucocitose por neutrofilia. Além de ocorrer elevação das enzimas hepáticas e hipercolesterolemia, desencadeada pela lipólise provocada por catecolaminas ou à presença de doenças endócrinas concomitantes, como hiperadrenocorticismo ou Diabetes mellitus (Carvalho \& Jericó, 2014).

Muitos feocromocitomas não são detectados clinicamente e são encontrados acidentalmente em celiotomia exploratória ou exame post-mortem, em outros casos, podem apresentar crise aguda com colapso cardiovascular ou ser causa de morte súbita (Morris, 2007).

O objetivo deste trabalho foi realizar o estudo de um caso post-mortem de feocromocitoma realizado em aula com os alunos de Patologia Especial, destacando os sinais clínicos que o paciente apresentou e evidenciando as características macroscópicas do tumor, assim como auxiliar o médico veterinário no diagnóstico prévio da doença.

\section{Relato de caso}

Uma cadela sem raça definida, com aproximadamente nove anos de idade, pesando $11 \mathrm{~kg}$ foi atendida no Hospital Veterinário da Universidade Regional do Noroeste do Estado - UNIJUí, apresentando hematomas cutâneos e perioculares. Apresentava-se apática, não se alimentava há quatro dias e 
demonstrava um quadro de polidipsia. O animal ficou internado para observação e coleta de sangue para realização de hemograma, ALT, albumina, FA, creatinina e ureia para avaliar as funções renal e hepática.

Sem ver evolução nos quinze dias de tratamento, a tutora decidiu optar pela eutanásia e solicitou exame de necropsia. Assim, o animal foi encaminhado para o Laboratório de Patologia Veterinária da UNIJUÍ.

\section{Resultados e discussão}

Estudos de Jericó et al. (2015) afirmam que as queixas frequentes na anamnese envolvem perda de peso, anorexia, depressão, assim como sinais respiratórios, sem especificidade das alterações para o diagnóstico de feocromocitoma.

Após diversas tentativas terapêuticas, a cadela seguia em estado apático, adípsico e anoréxico. Nos exames laboratoriais percebeu-se que o animal apresentou agravamento no quadro clínico, com eritrograma apresentando anemia normocítica e normocrômica regenerativa, com presença de precursores de células sanguíneas, com anisocitose e policromasia acentuadas e leucograma com leucocitose por neutrofilia com desvio à esquerda regenerativo, com monocitose e marcante trombocitopenia (Tabela 1).

Tabela 1. Hemograma e Proteína Plasmática total.

\begin{tabular}{|c|c|c|c|}
\hline Série Vermelha & \multicolumn{2}{|c|}{ Valor } & Referência* \\
\hline Eritrócitos (milhões $/ \mathrm{mm}^{3}$ ) & \multicolumn{2}{|c|}{3,64} & $5,5-8,5$ \\
\hline Hemoglobina (g/dL) & \multicolumn{2}{|c|}{8,7} & $12-18$ \\
\hline Hematócrito (\%) & \multicolumn{2}{|c|}{27,4} & $37-55$ \\
\hline VCM (fL) & \multicolumn{2}{|c|}{75,3} & $60-77$ \\
\hline $\mathrm{CHCM}(\%)$ & \multicolumn{2}{|c|}{31,8} & $32-36$ \\
\hline Série Branca & Relativo (\%) & Absoluto $\left(/ \mathrm{mm}^{3}\right)$ & Referência* \\
\hline Leucócitos totais & - & 37.000 & $6.000-17.000$ \\
\hline Neutrófilos não segmentados & 5 & 1.850 & $0-300$ \\
\hline Neutrófilos segmentados & 81 & 29.970 & $3.000-11.500$ \\
\hline Monócitos & 4 & 1.480 & $150-1350$ \\
\hline Linfócitos & 9 & 3.330 & $1.000-4.800$ \\
\hline Eosinófilos & 1 & 370 & $150-1250$ \\
\hline Basófilos & - & - & Raros \\
\hline Plaquetas $\left(10^{3} / \mu \mathrm{L}\right)$ & & 4 & $200-500$ \\
\hline Proteína plasmática total $(\mathrm{g} / \mathrm{dL})$ & & 6,4 & $6,0-8,0$ \\
\hline
\end{tabular}

Observações: Visualizados 14 metarrubrícitos em contagem de 100 leucócitos. Presença de anisocitose (+++), policromasia $(+++)$, corpúsculos de Howell-Jolly (+). Trombocitopenia confirmada em lâmina.

Morris (2007) afirmam que tumores podem apresentar sinais clínicos como depressão, alterações comportamentais, distúrbios de sede, apetite, ou regulação de temperatura, mancha contínua, pressionamento da cabeça, e andar em círculos. Alguns destes sinais coincidem com a apresentação do animal desde a anamnese até a piora do quadro clínico.

Gilson et al. (1994) estudaram 50 casos de feocromocitoma em cães e realizaram uma análise de predominância em exames clínicos. O hemograma apresentou anemia em 15\% dos casos, leucocitose em 26\% dos casos, leucopenia em um canino, e trombocitose em $8 \%$, elevação da alanina aminotransferase e aspartato aminotransferase séricas. A única correlação clínica foi que todos os cães com trombocitose tiveram sangramento tumoral crônico.

No exame bioquímico (Tabela 2) é possível analisar um aumento significativo da alanina amitrotransferase (ALT) e fosfatase alcalina (FA). 
Segundo Barthez et al. (1997), no exame bioquímico o aumento de ALT e AST é um achado comum nos casos de feocromocitoma, devido à presença de doenças concomitantes, como diabetes, hiperadrenocorticismo e hepatopatias.

Tabela 2. Exame bioquímico.

\begin{tabular}{lcc}
\hline Exame & Valor & Referência* \\
\hline Creatinina & $0.80 \mathrm{mg} / \mathrm{dL}$ & $0.5-1.5 \mathrm{mg} / \mathrm{dL}$ \\
ALT & $229 \mathrm{U} / \mathrm{L}$ & $21-102 \mathrm{U} / \mathrm{L}$ \\
FA & $1972 \mathrm{U} / \mathrm{L}^{*}$ & $20-156 \mathrm{U} / \mathrm{L}$ \\
\hline
\end{tabular}

Observações: Resultado repetido e confirmado.

Na necropsia, foram observadas numerosas áreas de hematomas no subcutâneo e musculatura (Figura 1A). Ao corte dos vasos o sangue fluía aquosamente (Figura 1B).

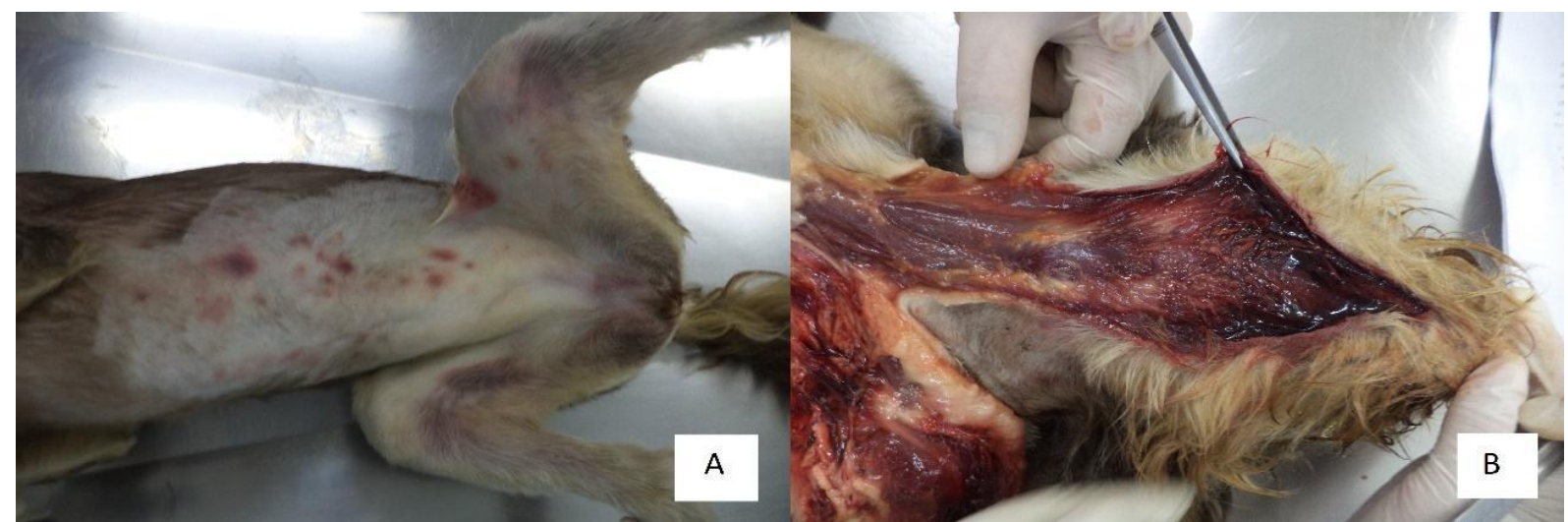

Figura 1. (A) Hematomas evidenciados na pele em região ventro-abdominal e em faces internas dos membros pélvicos do animal. (B) Fluidez sanguínea intensa percebida à dissecação da região mentoniana.

$\mathrm{Na}$ avaliação macroscópica do intestino delgado, atentou-se pelo aspecto pálido e às áreas de hemorragia (Figura 2A), sobretudo na porção pilórica (Figura 2B). No mesentério havia áreas hemorrágicas correspondentes a hematoma focal.

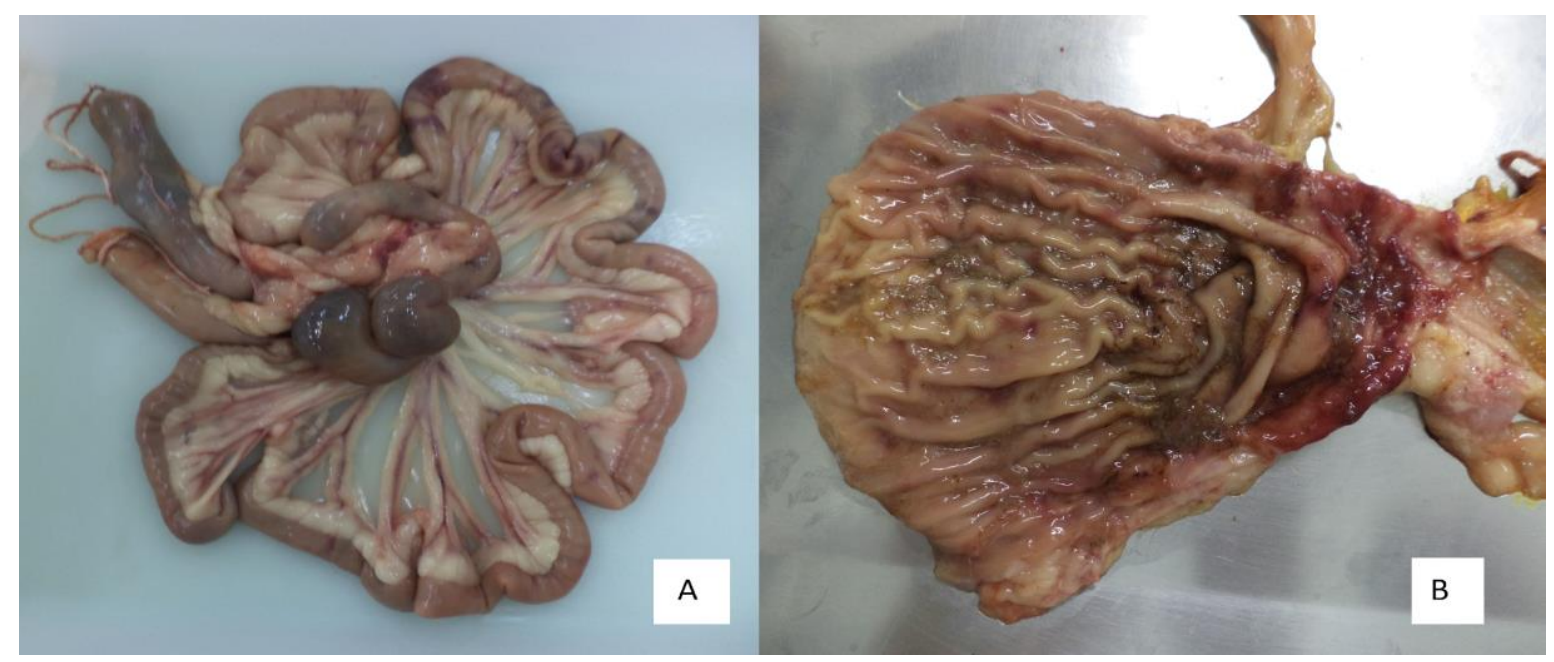

Figura 2. (A) Intestino dissecado de animal com áreas de hemorragia e palidez. (B) Estômago dissecado apresentando acentuada área de hemorragia em porção pilórica.

Na cavidade torácica havia $15 \mathrm{~mL}$ de sangue com aspecto aquoso (Figura 3B) e múltiplas petéquias no pulmão direito. O fígado se encontrava pálido, o baço apresentou bordas aumentadas e no estômago equimoses na superfície serosa (Figura 3A). No coração foi observado endocardiose nodular valvular esquerda. No pulmão, observou-se edema multifocal moderado (Figura 3A). 
Percebeu-se que a adrenal esquerda não apresentava alterações, contudo, a adrenal direita se encontrava aumentada de volume, com presença de nódulo e áreas de necrose na região interna da glândula (Figura 4).

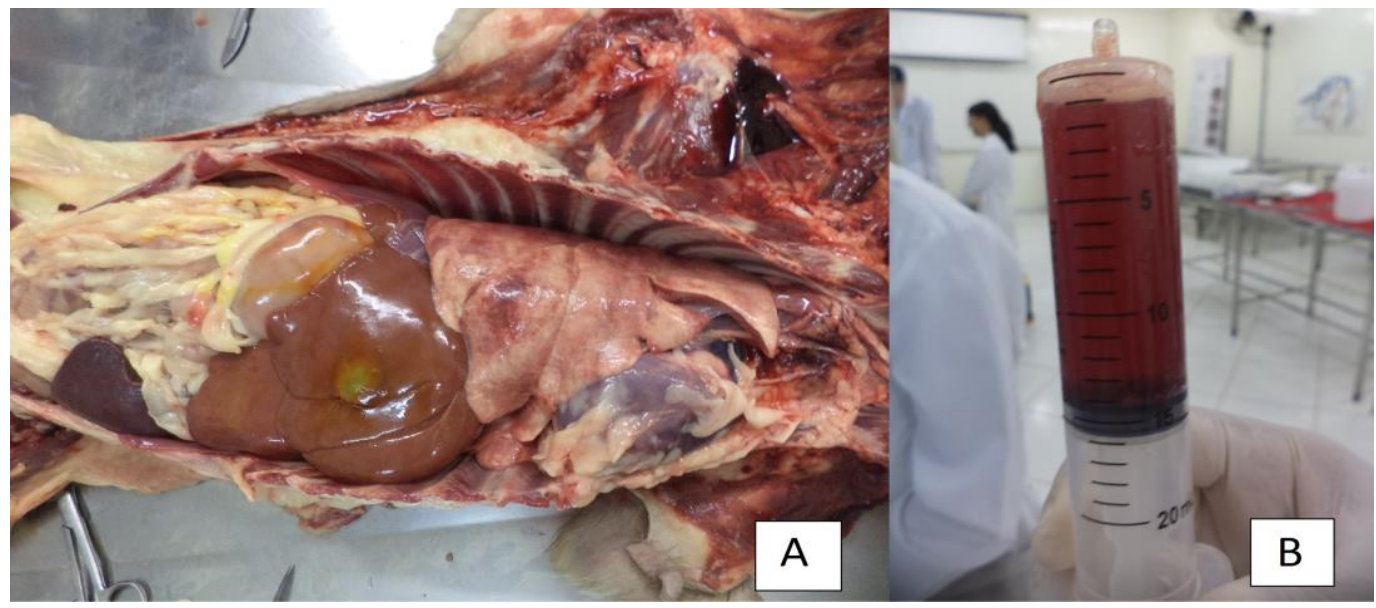

Figura 3. (A) Região tóraco-abdominal evidenciando pulmão direito com múltiplas petéquias e edema multifocal moderado, fígado pálido e baço com bordas aumentadas. (B) Seringa preenchida com 15 $\mathrm{ml}$ de sangue de aspecto aquoso referente a hemotórax.

Segundo Coelho et al. (2016), a histopatologia do feocromocitoma apresenta células que se alternam de pequenas, poliédricas ou cuboides a grandes e pleomórficas, com múltiplos núcleos hipercromáticos. O citoplasma é levemente eosinofílico, finamente granular e sem delimitação evidente. Nos feocromocitomas malignos, encontram-se numerosas áreas de necrose de coagulação e hemorragias.

$\mathrm{O}$ exame microscópico foi prejudicado devido à autólise marcada em diversos órgãos como fígado, baço, rins, coração, encéfalo, estômago, bexiga e intestino. A adrenal direita apresentou proliferação de células vacuolizadas focalmente extensa, similar ao encontrado na literatura, e autólise moderada.

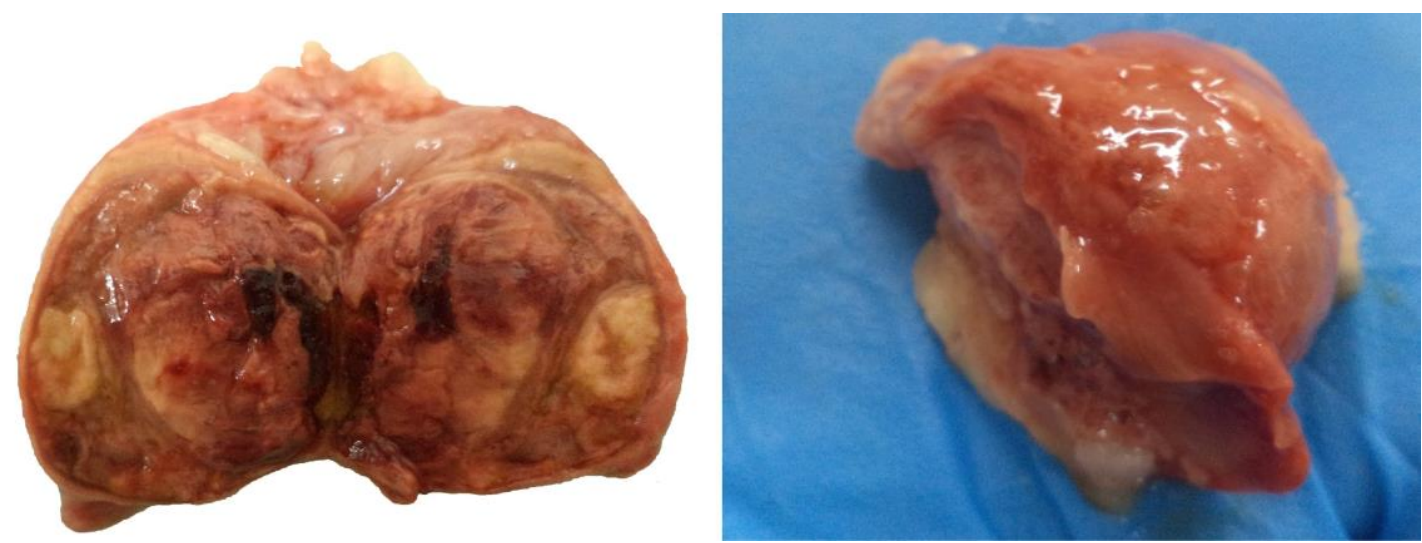

Figura 4. Adrenal direita com aumento de volume, presença de nódulo e áreas de necrose na porção interna.

Jones et al. (2000) afirmam que a autólise é um processo de autodigestão celular e resulta em coagulação e degradação de proteínas celulares e ácidos nucleicos no núcleo e citosol. No presente caso não foi possível realizar a necropsia logo após a eutanásia, o que evitaria o processo autolítico.

A cirurgia é o tratamento de escolha, e deve ser realizada com cirurgiões e anestesistas com experiência, devido ao potencial risco de complicações secundárias à secreção de catecolaminas (Daleck \& Nardi, 2016). Quando a ressecção cirúrgica não é possível, o tratamento clínico pode reduzir o número de paroxismos e as lesões de órgãos-alvo com relativa melhora da expectativa de vida (Malachias \& Vinicius, 2002).

A quimioterapia não foi analisada como tratamento para a neoplasia no caso avaliado. $\mathrm{O}$ estudo de Bommarito et al. (2011) consideraram a radioterapia utilizando a metaiodobenzilguanidina 
radiomarcada com iodo 131 para o tratamento de um cão com feocromocitoma inoperável, o qual estabilizou a doença por um mês e meio.

Exames de raios- $\mathrm{X}$ abdominais e ultrassonográficos podem ser utilizados para constatar o aumento da glândula adrenal ou massas adrenais, possíveis metástases pulmonares e abdominais, cardiomegalia e sinais de insuficiência cardíaca congestiva (Morris, 2007).

Morris (2007) também afirmam que, apesar de serem exames complementares de alto custo, a ressonância magnética e a tomografia computadorizada fornecem imagens mais detalhadas das glândulas adrenais e podem contribuir para a acurácia do diagnóstico.

\section{Conclusão}

Apesar da ocorrência rara em cães, o feocromocitoma é uma neoplasia relevante a qual o médico veterinário deve estar atento. Neste caso, o diagnóstico foi obtido pelo histórico, sinais clínicos e exame post-mortem, os quais foram cruciais para identificação da causa do quadro clínico-patológico que determinou a eutanásia.

\section{Referências}

Almeida, V. A., \& Silva, F. L. (2009). Feocromocitoma maligno em cão: relato de caso. Revista Brasileira de Medicina Veterinária, 31(4), 237-242.

Barthez, P. Y., Marks, S. L., Woo, J., Feldman, E. C., \& Matteucci, M. (1997). Pheochromocytoma in Dogs: 61 Cases (1984-1995). Journal of Veterinary Internal Medicine, 11(5), 272-278. https://doi.org/10.1111/j.1939-1676.1997.tb00464.x

Bommarito, D. A., Lattimer, J. C., Selting, K. A., Henry, C. J., Cohen, M., \& Johnson, G. C. (2011). Treatment of a Malignant Pheochromocytoma in a Dog Using ${ }^{131}$ I Metaiodobenzylguanidine. Journal of the American Animal Hospital Association, 47(6), e188-e194. https://doi.org/10.5326/JAAHA-MS-5605

Capen, C. C. (2002). Tumors of the endocrine glands. In: Meuten, D. J. (ed.) Tumors in Domestic Animals. Ames, Raleigh, NC, USA.

Carvalho, C. F., \& Jericó, M. M. (2014). Adrenais. Ultrassonografia Em Pequenos Animais. Capitulo, 9, 101-107.

Coelho, H. E., Santos, R. L., \& Alessi, A. C. (2016). Patologia veterinária. Coelho.

Coelho, Humberto Eustáquio, Carvalho, T. F., Nunes, J. B., Silva, D. C. B., Alberto, H., Barbosa, C. H. G., Rezende, R. S., \& Machado, F. M. E. (2011). Ocorrência de feocromocitoma em adrenal com metástase no intestino e rim de um cão-relato de caso. PUBVET, 5, Art-1245.

Daleck, C. R., \& Nardi, A. B. (2016). Oncologia em cães e gatos . Grupo Gen-Editora Roca Ltda.

Gilson, S. D., Withrow, S. J., Wheeler, S. L., \& Twedt, D. C. (1994). Pheochromocytoma in 50 Dogs. Journal of Veterinary Internal Medicine, 8(3), 228-232. https://doi.org/10.1111/j.1939-1676.1994.tb03222.x

Jericó, M. M., Kogika, M. M., \& Andrade Neto, J. P. (2015). Tratado de medicina interna de cães e gatos. Guanabara Koogan.

Jones, T. C., Hunter, R. D., \& King, N. W. (2000). Patologia veterinária. Manole, São Paulo, Brasil.

Maher, E. R., \& McNiel, E. A. (1997). Pheochromocytoma in Dogs and Cats. Veterinary Clinics of North America: Small Animal Practice, 27(2), 359-380. https://doi.org/10.1016/S0195-5616(97)50037-4

Malachias, M. V, \& Vinicius, B. (2002). Feocromocitoma-diagnóstico e tratamento. Rev Bras Hipertens, 9(2), 160-164.

Morris, J. (2007). Oncologia em pequenos animais. Editora Roca.

\section{Histórico do artigo:}

Recebido: 14 de setembro, 2020

Aprovado: 22 de outubro, 2020.

Disponível online: 17 de novembro, 2020
Licenciamento: Este artigoé publicado na modalidade Acesso Aberto sob a licença Creative Commons Atribuição 4.0 (CC-BY 4.0), a qual permite uso irrestrito, distribuição, reprodução em qualquer meio, desde que $\mathrm{o}$ autor e a fonte sejam devidamente creditados. 